\title{
Formulation of Transfersomal Green Tea (Camellia sinensis L. Kuntze) Leaves Extract Cream and in vitro Penetration Study Using Franz Diffussion Cell
}

\author{
Delly Ramadon*, Marsha Harme, Effionora Anwar \\ Laboratory of Pharmaceutics and Pharmaceutical Technology Development, Faculty of Pharmacy, Universitas Indonesia, Depok, 16424, INDONESIA.
}

\begin{abstract}
Introduction: Green tea is a natural ingredient that contains polyphenolic compounds in the form of catechin derivatives known as epigallocatechin gallate (EGCG). It has an antioxidant activity that is beneficial for body health. However, EGCG has a considerable molecular weight and high hydrophilicity resulting in the difficulty of skin penetration. The aim of this study was to improve EGCG penetration through the skin by using the formation of lipid nanovesicles, called transfersomes, that was formulated into a cream dosage form. Methods: Transfersomes were prepared by thin layer hydration method in three formulations with different concentration of phospholipid and surfactant. The amount of green tea leaves extract used for all formulations was same, (equal to 3\% EGCG). All transfersomes formulation was characterized their physical properties, and the most promising formulation was chosen to be formulated into a cream dosage form. A cream contained untreated extract was prepared as a control. The in vitro penetration study of EGCG from both creams was evaluated using Franz diffusion cells with the abdomen skin of SpragueDawley rats as a membrane between the compartments. Results and Discussion: The results showed that F1 was the most promising and optimal formulation with a spherical shape, particle size of $80.6 \mathrm{~nm}$, a polydispersity
\end{abstract}

index of 0.214 , a zeta potential at $-48.2 \pm 1.78 \mathrm{mV}$, and the highest entrapment efficiency of $49.36 \pm 4.03 \%$. The cumulative amount of EGCG penetrated from transfersomal and non transfersomal cream were 1003.61 $\pm 157.93 \mathrm{\mu g} / \mathrm{cm}^{2}$ and $400.09 \pm 47.53 \mu \mathrm{g} / \mathrm{cm}^{2}$, respectively $(P<0.05)$. Conclusion: To summarize, this study demonstrated that formulation of green tea leaves extract into a transfersomal cream dosage form could increase the amount of EGCG penetrated through the skin.

Key words: Cream, Epigallocatechin gallate, Franz diffusion cell, Green tea leaves extract, Transfersome.

\section{Correspondence}

Delly Ramadon, Faculty of Pharmacy, Universitas Indonesia, Depok, 16424 , West Java, INDONESIA.

Phone: +62-21-7270031, 7864049, 78884557

Email: delly.ramadon@farmasi.ui.ac.id

DOI: 10.5530/jyp.2018.2s.12

\section{INTRODUCTION}

Green tea (Camellia sinensis L. Kuntze) is one of the natural products which has been widely used for many purposes due to its health benefits. Green tea contains about 4,000 bioactive components. ${ }^{1}$ The highest concentration of polyphenolic compounds in green tea plant is in the form of catechin groups and they provide some pharmacological benefits. One of the catechin derived compounds found in most green tea leaves is epigallocatechin gallate (EGCG). ${ }^{2}$ This compound has a high antioxidant activity to protect the skin from sun exposure and contribute in preventing some degenerative diseases. ${ }^{3}$

However, EGCG has a low absorption rate in the small intestine, less than $5 \%$ of EGCG enters the systemic circulation. ${ }^{4}$ The unabsorbed EGCG to the systemic circulation will be thrown away to the colon and degraded by intestinal microflora. ${ }^{5}$ Choosing an alternative drug administration route such as transdermal drug delivery system could be a solution to overcome these problems above. Transdermal drug delivery system is defined as the delivery of drugs through the skin into the systemic circulation. ${ }^{6}$ This route is applied to avoid the gastrointestinal degradation, first pass metabolism, and drug level fluctuations in the blood. ${ }^{7}$

To provide optimal antioxidant effects, the bioactive component of green tea, in this case EGCG, should penetrate into the skin. However, EGCG has a relatively high polarity $(\log \mathrm{P}=0.48),{ }^{8}$ and a considerable molecular weight $(458.37 \mathrm{Da})$ that becomes an issue in skin penetration. ${ }^{9}$ The various attempts have been made by some researchers to improve EGCG penetration capability into the stratum corneum, by making synthetic derivatives from EGCG.$^{10}$ Physical effort has also been made, in order to facilitate the transit of EGCG which is a hydrophilic compound through the stratum corneum. It can be done by penetrating enhancer tools such as iontophoresis, sonophoresis, or microneedle technology. Although a number of such efforts have been successful in increasing EGCG penetration into the skin, it has some drawbacks, they are more complex, less efficient, need a long time preparations and costly tools are required. ${ }^{11}$

Therefore, formulation of EGCG of green tea leaves extract into a lipid nanovesicle (transfersomes) could be applied to increase its penetration through the skin. Transfersome is a deformable elastic vesicle, composed of phospholipids and surfactants. Surfactant increased the deformability of transfersomes. The unstable lipid bilayer conformation in the presence of surfactants resulted in increasing the vesicle deformability. ${ }^{12}$ Furthermore, transfersomes could act as efficient carriers for a deeper layer of the skin. It can be used to deliver drugs and genetic material in the form of chemicals and natural materials, and it has the ability to entrap hydrophilic and lipophilic molecules to be target to organs or tissues. ${ }^{13}$ Therefore surfactant was used to improve the drugs penetration through the skin via skin layers until they reach the systemic circulation system. ${ }^{14}$ The previous research has formulated green tea leaves extract into various forms of nanovesicle, such as ethosome, ${ }^{7}$ transfersome, ${ }^{6}$ and transethosome,${ }^{25}$ which then incorporated into a gel dosage form. In this study, a selected transfersome formulation of green tea leaves extract 
(Camellia sinensis L. Kuntze) was formulated into a cream dosage form to increase the penetration of EGCG. An in vitro penetration study using Franz diffusion Cells was conducted to perform the ability of the transfersomal cream in increasing the amount of EGCG penetrated through the skin. A non-transfersomal green tea leaves extract cream was prepared as a control. Moreover, the quantification of EGCG penetrated in the in vitro penetration study was analyzed using an reverse-phase high performance liquid chromatography (RP-HPLC) method.

\section{MATERIALS AND METHODS}

\section{Materials}

Green tea leaves extract (Camellia sinensis L. Kuntze) (Andy Biotech Co. Ltd., China), EGCG standard (Sigma-Aldrich, Singapore), Lipoid P 30 with purity of $97 \%$ phospholipids containing $30 \%$ phosphatidylcholine (kindly provided by Lipoid GmbH, Germany), solvents and other chemicals were analytical grade.

\section{EGCG assay in green tea leaves extract}

EGCG analysis was carried out in a RP-HPLC system using a C-18 column $(250 \times 4.6 \mathrm{~mm})$ with a flow rate of $1.0 \mathrm{~mL} / \mathrm{min}$. Mobile phase was the mixture of acetic acid solution (1\%, v/v) and acetonitrile $(87: 13, \mathrm{v} / \mathrm{v})$ with a final $\mathrm{pH}$ was 3.5 . The mobile phase was filtered through $0.45 \mathrm{~mm}$ membrane filter, and degassed prior to utilization. The injection volume was $20 \mu \mathrm{L}$ with a total runtime of $20 \mathrm{~min}$. The column temperature was set at $20 \pm 3.0^{\circ} \mathrm{C}$. EGCG stock solution was prepared by dissolving 10.0 $\mathrm{mg}$ standard in $100 \mathrm{~mL}$ of the mobile phase. The stock solution was further diluted to get six concentration of standard solutions. The solution was then injected into the HPLC, and a calibration curve was made by plotting the peak area to the standard concentration, resulting a linear curve, $y=a+b x$, with $\mathrm{r}$ as determinant of linearity. The sample solution of green tea leaves extract was prepared in concentration of $40 \mu \mathrm{g} /$ $\mathrm{mL}$ in three replicates. The area obtained was then plotted into a linear regression equation to obtain the measured concentration to be used in calculating the EGCG level in the sample.

$$
\text { EGCG level }(\%)=\frac{\text { ECGG concentration measured }}{\text { EGCG theoretical concentration }} \times 100
$$

The levels obtained were then used to calculate the dose of green tea leaves extract in the cream.

\section{Antioxidant activity test of green tea leaves extract}

The positive reference solution of ascorbic acid and green tea leaves extract solution were prepared in different concentration. Diphenyl picrylhydrazyl (DPPH) $100 \mu \mathrm{g} / \mathrm{mL}(1.0 \mathrm{~mL})$ and methanol $(2.0 \mathrm{~mL})$ were added into $1.0 \mathrm{~mL}$ of each sample solution. Methanol $(3.0 \mathrm{~mL})$ and DPPH $100 \mu \mathrm{g} / \mathrm{mL}(1.0 \mathrm{~mL})$ solution was made as blank. The mixture was shaken and incubated at a room temperature for 30 mins. The antioxidant activity was determined by measuring the absorbance of each sample by UV-Vis spectrophotometer with an optimum wavelength of $514 \mathrm{~nm}$. The results obtained were used to calculate the inhibition percentage of green tea leaves extract against DPPH.

\section{Transfersome formulation}

Transfersome formulations can be seen in Table 1. Transfersome was prepared by a thin layer hydration method. Lipoid P 30 and Span 80 were dissolved in dichloromethane. The dissolved phospholipid and surfactant were poured into a round-bottom flask. Dichloromethane mixture was then evaporated by a rotary vacuum evaporator at a temperature of $37 \pm 1^{\circ} \mathrm{C}$. Evaporation was done to form a thin film on the inner wall of round-bottom flask. Nitrogen gas was flowed into the thin layer and
Table 1: Transfersome formulations.

\begin{tabular}{cccc}
\hline \multirow{2}{*}{ Substances } & \multicolumn{3}{c}{ Concentration (\% w/v) } \\
\cline { 2 - 4 } & F1 & F2 & F3 \\
\hline Green tea extract & Equal to EGCG & Equal to EGCG & Equal to EGCG \\
Lipoid P30 & 3.0 & 3.0 & 3.0 \\
Span 80 & 9.50 & 9.00 & 8.50 \\
$\begin{array}{c}\text { Phosphate buffer } \\
\text { pH 5.5 }\end{array}$ & 0.50 & 1.00 & 1.50 \\
\hline
\end{tabular}

the film was then stored in the refrigerator for $24 \mathrm{~h}$. The thin layer was hydrated with a phosphate buffer solution ( $\mathrm{pH}$ 5.5) containing green tea leaves extract. The hydration process was carried out at $37^{\circ} \mathrm{C}$ with rotation speed at $150 \mathrm{rpm}$ with glass beads to remove and erode the thin layer on a round flask wall. The particle size was reduced by ultrasonication at $20 \mathrm{kHz}$ for $10-15$ min once the transfersome suspension was formed.

\section{Transfersome characterization}

The obtained transfersomes were characterized their particle size distribution, polydispersity index, zeta potential, and the entrapment efficiency.

\section{Morphology of transfersomes}

Morphology of the trasnfersomes prepared was analyzed by using a transmission electron microscope (TEM) (FEI Tecnai type G2 20 S-TWIN). Samples were shed on a carbon-coated copper grid, the droplets were dried at room temperature and colored using phosphotungstic acid solution. The dried droplets were observed under a microscope at the acceleration voltage of $200 \mathrm{kV}$ and temperature of $20^{\circ} \mathrm{C}$ with 100,000 magnification

\section{Particle size distribution, polydispersity index, and zeta potential}

The particle size distribution and zeta potential of all transfersome formulations were measured by dynamic light scattering (DLS) particle size analyzer with a computerized system (Malvern, Zetasizer). The zeta potential measurement was also performed. Each measurement was performed three times.

\section{The entrapment efficiency}

Transfersome suspension $(0.5 \mathrm{~mL})$ was taken and diluted with phosphate buffer pH $5.5(1.0 \mathrm{~mL})$, then centrifuged at 14,000 rpm for $3 \times 30$ mins. The supernatant was collected and diluted with ethanol. The solution was injected into the HPLC injector. Entrapment efficiency was calculated by the following formula:

$\% \mathrm{EE}=\frac{\text { Total EGCG in the suspension }- \text { ECGG concentration measured }}{\text { Total EGCG in the suspension }} \times 100$

\section{Cream preparation}

The melting or fusion method was used for manufacturing the cream. The oil phase was melted using a water bath at a temperature of $70-75^{\circ} \mathrm{C}$. The water was heated until the temperature reached $\pm 70^{\circ} \mathrm{C}$, and used to dissolve the water phase. The oil and water phase were then mixed using a homogenizer with a speed of $1000 \mathrm{rpm}$ to form a cream base. The active substance (green tea leaves extract loaded transfersome or green tea leaves extract solution for the control cream) was added gradually 
Table 2: Cream formulation.

\begin{tabular}{ccc} 
Substances & \multicolumn{2}{c}{ Concentration (\% w/w) } \\
\cline { 2 - 3 } & TC & NTC \\
\hline Transfersome green tea leaves & Equal to EGCG 1 & - \\
extract & - & Equal to EGCG 1 \\
Green tea extract & 2.5 & 2.5 \\
Cetyl alcohol & 3 & 3 \\
Isopropyl myristate & 10 & 10 \\
Stearic acid & 2 & 2 \\
Triethanolamine (TEA) & 10 & 10 \\
Propylene glycol & 0.1 & 0.1 \\
Sodium Sulfite & 10 & 10 \\
Dimethicone & 0.5 & 0.5 \\
Butylated hydroxytoluene & Ad 100 & Ad 100 \\
Aquadest & &
\end{tabular}

into the cream base. The $\mathrm{pH}$ of the cream was observed to obtain the skin $\mathrm{pH}$ range (4-5.5). The cream was made in two formulations, called transfersomal green tea leaves extract cream (TC) and non-transfersomal cream (NTC) that contained untreated extract. Both cream formulations can be seen in Table 2 .

\section{Physicochemical evaluation of gel dosage forms}

Physicochemical evaluations of cream, including organoleptic test (color and odor), homogeneity, $\mathrm{pH}$, viscosity and rheology properties, were conducted.

\section{In vitro penetration test}

The abdomen skin of 2-3 months female Sprague-Dawley rats with a weight of 200-250 g was used as a membrane in the test. In this study, all methods for sacrificing the animals had been approved by Ethical Clearance Committee of Cipto Mangunkusumo Hospital, Faculty of Medicine, Universitas Indonesia No. 313/UN.2F1/ETIK/2017. In vitro penetration test was performed by using Franz diffusion cells with a diffusion area of $2.01 \mathrm{~cm}^{2}$ and a compartment volume of $15 \mathrm{~mL}$. The receptor compartment was filled with phosphate buffer $\mathrm{pH} 5.5$ and stirred with a magnetic stirrer at speed of $250 \mathrm{rpm}$. The skin was placed on the donor compartment receptor with the position of the stratum corneum facing upwards. Samples tested in this study were transfersome suspension (TS) and green tea leaves extract solution in water (ES) which contained green tea extract equal to $1 \%$ EGCG, and TC and NTC containing extract equal to $3 \%$ EGCG. Each sample $(1.0 \mathrm{~g})$ of them was applied onto the skin surface. An aliquot $(2.0 \mathrm{~mL})$ was drawn from receptor compartment using a syringe at several time intervals $(10,30,60,120,240,360,480$, $600,720,840,960,1080,1200,1320$, and $1440 \mathrm{~min}$ ) and the receptor compartment was refilled with the same amount of phosphate buffer $\mathrm{pH}$ 5.5. The aliquot was inserted into the vial and its concentration was measured by high performance liquid chromatography (HPLC).

\section{Statistical Analysis}

All statistical analysis of this study were calculated using GraphPad Prism version 7.0 with unpaired t-test using the significance of $P$ value less than 0.05 .

\section{RESULTS}

\section{EGCG assay in green tea leaves extract}

The linear regression equation of the calibration curve was $y=29235 x-$ 338074 with correlation coefficient value (r) of 0.9940 . The result showed
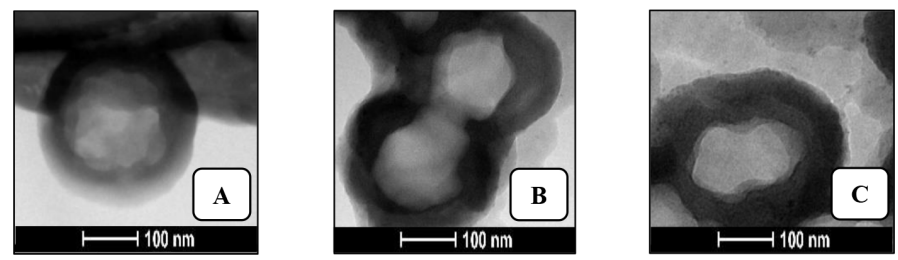

Figure 1: Morphology of vesicles. (A) F1, (B) F2 and (C) F3.

Table 3: Summary of ethosomes characterization results.

\begin{tabular}{cccccc}
\hline Formula & Morphology & $\begin{array}{c}\text { Z-average Polydispersity } \\
(\mathrm{nm})\end{array}$ & $\begin{array}{c}\text { Zeta } \\
\text { index }\end{array}$ & $\begin{array}{c}\text { Entrapment } \\
(\mathrm{mV})\end{array}$ & $\begin{array}{c}\text { Efficiency } \\
(\%)\end{array}$ \\
\hline F1 & Spherical shape & 80.6 & 0.214 & $-48.2 \pm 1.78$ & $49.36 \pm 4.03$ \\
F2 & Spherical shape & 88.27 & 0.305 & $-47.87 \pm 3.4339 .26 \pm 0.67$ \\
F3 & Spherical shape & 95.67 & 0.261 & $-41.1 \pm 7.06$ & $32.15 \pm 1.49$ \\
\hline
\end{tabular}

that the calibration curve was linear because the correlation coefficient was close to one. The EGCG levels of green tea leaves extract samples was $53.77 \% \pm 0.07 \mathrm{w} / \mathrm{w}$.

\section{Antioxidant activity test of green tea leaves extract}

The $\mathrm{IC}_{50}$ value of green tea leaves extract was $1.32 \mu \mathrm{g} / \mathrm{mL}$, while the $\mathrm{IC}_{50}$ value of ascorbic acid was $2.54 \mu \mathrm{g} / \mathrm{mL}$. The smaller the $\mathrm{IC}_{50}$, the higher the antioxidant activity of a compound. ${ }^{15}$

\section{Characterization of transfersom}

Based on the result shown in Figure 1, F1 had a spherical shape, but F2 and F3 had an irregular shape. Particle size, zeta potential, and polydispersity index can be seen in Table 3.

\section{The entrapment efficiency}

The entrapment efficiency obtained for F1, F2, and F3 were $49.36 \pm 4.03$, $39.26 \pm 0.67$, and $32.15 \pm 1.49 \%$, respectively.

\section{Physicochemical evaluation of cream dosage forms}

Based on the physical appearance observation, TC and NTC were similar in color, they were brownish white (Pantone 4685 PC) ${ }^{16}$ Both creams produced the scent of green tea leaves extract, while NTC had a stronger scent. The $\mathrm{pH}$ value of TC and NTC were $5.59 \pm 0.02$ and $5.65 \pm 0.05$, respectively. Both preparations were in the skin $\mathrm{pH}$ range (4.5-6.5). In the viscosity measurements with rotation speed of $20 \mathrm{rpm}$, the viscosity of TC and NTC were 12000 and 11200 cps.

\section{In vitro penetration test}

As a control of TC and NTC, an in vitro penetration test for transfersome suspension (TS) and green tea leaves extract solution (ES) was performed beforehand. According to Figure 2, it showed that after 24 $\mathrm{h}$ sampling, the number of cumulative EGCG penetrated through the mouse skin membrane from TS and ES were $5357.32 \pm 1027.36 \mu \mathrm{g} / \mathrm{cm}^{2}$ and $2965.85 \pm 1040.54 \mu \mathrm{g} / \mathrm{cm}^{2}$, respectively $(\mathrm{P}=0.0472, \mathrm{P}<0.05)$.

In addition, another important parameter of the in vitro penetration study is flux value. The flux value was obtained from the slope or slope taken from the steady state following the Fick I law. ${ }^{17}$ Based on Figure 3, the average flux value of TS and ES were $245.49 \pm 45.29 \mu \mathrm{g} / \mathrm{cm}^{2} / \mathrm{h}$ and $141.52 \pm 50.51 \mu \mathrm{g} / \mathrm{cm}^{2} / \mathrm{h}$, respectively $(\mathrm{P}=0.0567, \mathrm{P}>0.05)$.

Further tests were performed on TC and NTC. Based on Figure 4, it can be seen that cumulative amount of EGCG penetrated for $24 \mathrm{~h}$ between TC and NTC preparations. In TC preparations, the cumulative EGCG 


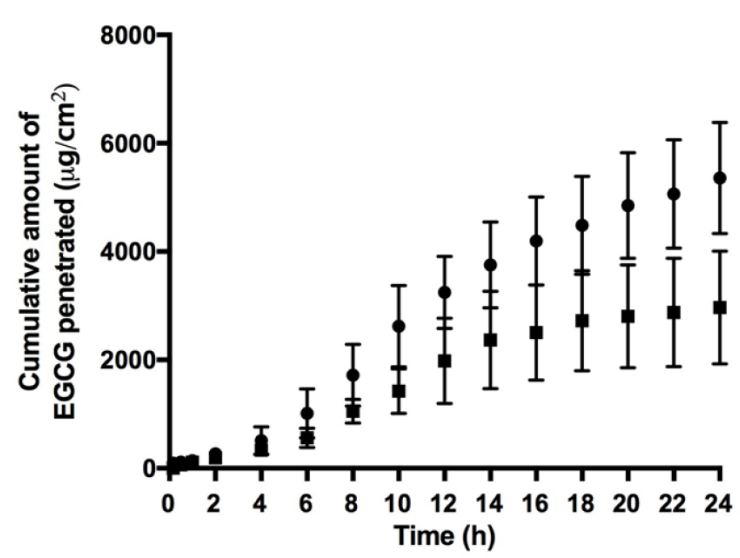

Figure 2: EGCG cumulative graph from (TS) transfersome suspension and (ES) extract solution $(n=3)$.

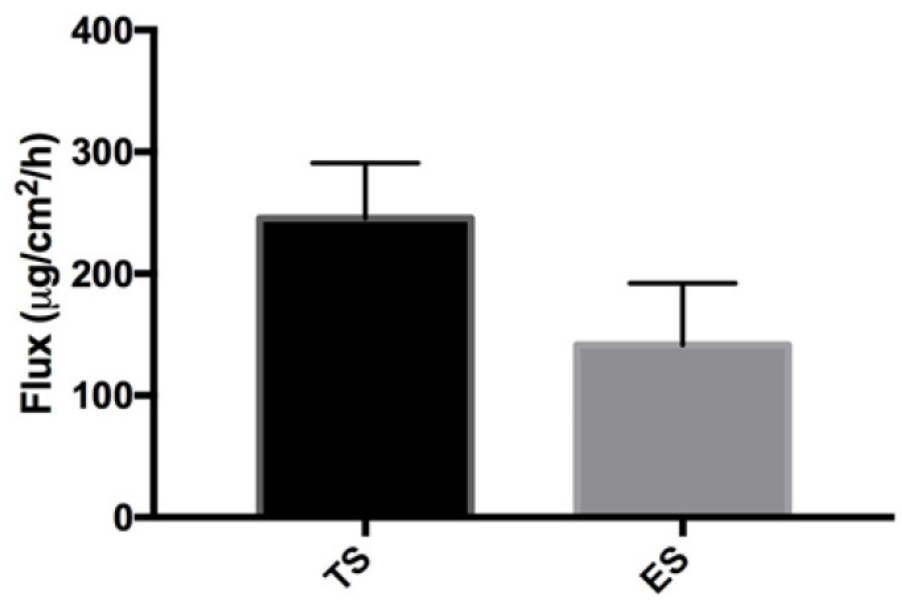

Formulations

Figure 3: EGCG flux from (TS) transfersome suspension and (ES) extract solution $(n=3)$.

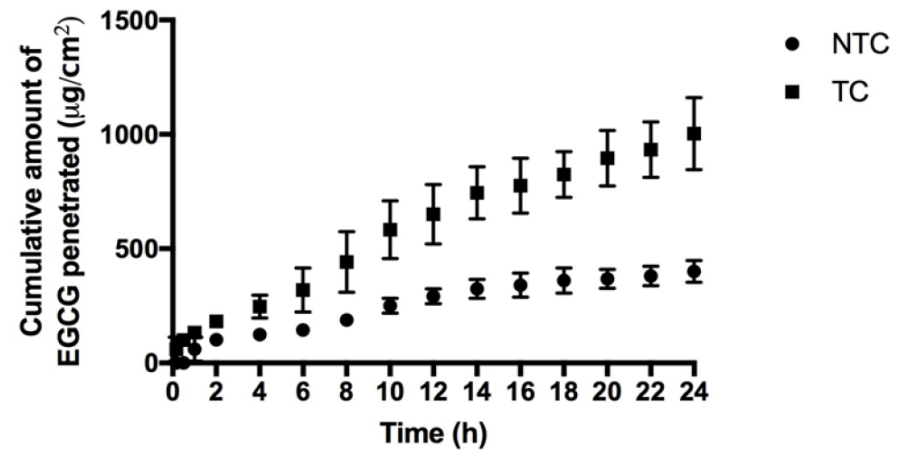

Figure 4: EGCG cumulative graph from (TC) transfersomal cream and (NTC) non-transfersomal cream $(n=3)$.

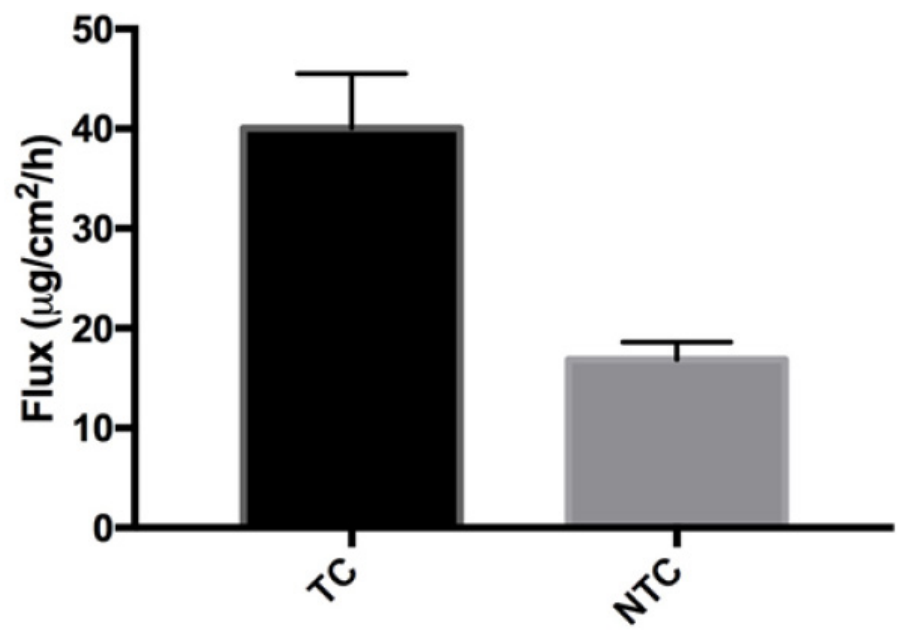

Formulations

Figure 5 : EGCG flux from (TC) transfersomal cream and (NTC) non-transfersomal cream $(n=3)$.

reached $1003.61 \pm 157.93 \mu \mathrm{g} / \mathrm{cm}^{2}$, while the NTC preparation was only at $400.09 \pm 47.53 \mu \mathrm{g} / \mathrm{cm}^{2}(\mathrm{P}=0.0032, \mathrm{P}<0.05)$.

Based on Figure 5, the average flux value of TC and NTC were $40.08 \pm$ $5.45 \mu \mathrm{g} / \mathrm{cm}^{2} / \mathrm{h}$ and $16.83 \pm 1.79 \mu \mathrm{g} / \mathrm{cm}^{2} / \mathrm{h}$, respectively $(\mathrm{P}=0.0022, \mathrm{P}<0.05)$

\section{DISCUSSION}

\section{EGCG assay in green tea leaves extract}

In this study, EGCG was separated by using RP-HPLC. A C-18 column was used as the stationary phase because EGCG from green tea leaves extract was very polar, so the polar mobile phase, in this case a mixture of acetic acid-acetonitrile $(87: 13 \mathrm{v} / \mathrm{v})^{18}$ was used to elute EGCG into the HPLC detector. The results of this experiment was used to determine the amount of green tea extract incorporated into transfersomes and cream.

\section{Antioxidant activity test of green tea leaves extract}

The results above showed that green tea leaves extract had higher antioxidant activity than ascorbic acid as a positive control, it was due to the smaller $\mathrm{IC}_{50}$ value of green tea leaves extract. Green tea leaves extract has a very strong antioxidant activity because it has IC50 value less than $10 \mu \mathrm{g} / \mathrm{mL} .{ }^{19}$ The antioxidant activity of EGCG in green tea leaves extract was expressed from the presence of $\mathrm{OH}$ groups located in positions 3, 4 , and 5 in the flavonoid $\mathrm{B}$ ring. This $\mathrm{OH}$ groups would reduce the free radical compound of $\mathrm{DPPH} .{ }^{20}$

\section{Transfersome formulation}

The main components of transfersomes were phospholipid and surfactant. The increase of the vesicle penetration into the skin could be achieved due to the properties of phospholipid which had a similar structure and partition coefficient to the lipid bilayer of the skin, and the application of surfactant as penetration enhancer which has the ability to increase vesicle deformability. ${ }^{21}$ Phosphate buffer at $\mathrm{pH} 5.5$ was selected based on the stability of EGCG at low $\mathrm{pH}(<\mathrm{pH} 6) .{ }^{22}$ The suspension was then sonicated to decrease the particles size.

\section{Characterization of transfersom}

Vesicle size must be smaller than $300 \mathrm{~nm}$ to penetrate through the deepest skin layer. ${ }^{23}$ All formulations met this requirement because they had particle size under $300 \mathrm{~nm}$. Another important physical property was 
the value of polydispersity index (PDI). PDI was defined as the degree of heterogeneity of particles with the acceptance PDI value was $<0.5 .^{24}$ The smaller PDI value closer to zero, the smaller the degree of heterogeneity of particle size, and all formulations had PDI value $<0.5$. Zeta potential of vesicle suspension was considered good when the value was greater than $+30 \mathrm{mV}$ or smaller than $-30 \mathrm{mV}^{25}$ It is because they would have tend to repel each other, and they would not aggregate to become a larger particle. ${ }^{26}$ The value of zeta potential for all formulations were less than $-30 \mathrm{mV}$. It indicated that all formulations might have a good stability. The zeta potential of suspension can be affected by $\mathrm{pH}$ of the solvent used, charge of drugs, and conductivity. Negative charge of zeta potential may be associated to the charge of drugs entrapped (in this case extract containing EGCG), neutral charge of the phospholipids used and the medium of suspension..$^{27}$ Furthermore, Sou found that a negative charge of zeta potential causes an increase of entrapment capacity. ${ }^{28}$ The result in this research was in line with the theory. As seen in Table 3, F1 had the lowest zeta potential among other formulations and it had the highest $\%$ EE too.

\section{The entrapment efficiency}

F1 was chosen to be incorporated into cream dosage form and suggested to be more efficient due to the less free extract were not entrapped in the suspension than F2 or F3. Chaudhary et al. found that entrapment efficiency of transfersomes can be improved by increasing the lipid concentration of decreasing the concentration of surfactant..$^{29}$ This is due to the possible coexistence of mixed micelles and vesicles at higher concentrations of surfactant, with the consequence of lower drug entrapment in mixed micelles. ${ }^{30}$ Therefore, F1 with the lowest concentration of surfactant had the highest entrapment efficiency than F2 and F3.

\section{Formulation of selected transfersome}

A transfersome formulation which had a spherical morphology, the highest percentage of entrapped drug, nano-sized ( $<300 \mathrm{~nm}$ ), polydispersity index $<0.5$ and zeta potential is more negative than -30 or more positive than $+30 \mathrm{mV}$ was chosen to be incorporated into cream dosage form. From the characterization performed, the selected formulation was F1 because of its spherical shape with particle size of $80.6 \mathrm{~nm}$, polydispersity index of 0.214 , zeta potential of $-41.1 \pm 7.06 \mathrm{mV}$, and the highest percentage of drug entrapped $(49.36 \pm 4.03 \%)$.

\section{Physicochemical evaluation of cream dosage forms}

TC and NTC had similar in color and $\mathrm{pH}$, its is due to transfersome formulations did not affect the color of the cream and the $\mathrm{pH}$. TC had a higher viscosity than NTC, it was due to the presence of phospholipid in formulations. Rheogram of TC and NTC were thixotropic with a plastic flow. A plastic flow curve does not pass through the point (0.0) and has a yield value. Yield value is a straight line extrapolated from the curve straight to the axis of the shear stress. Preparations that had plastic flow would not flow when the shear stress did not pass the yield value. Thixotropic indicated that the decline curve on the left ascending curve showed that after a shear stress was given, the structure took time to get back to the original condition. ${ }^{31}$

\section{In vitro penetration test}

Based on the result above, the comparison P value of TS and ES showed that the amount of EGCG penetrated increased along with the formulation of green tea leaves extract in the form of lipid nanovesicles (transfersome), but did not increase the rate of EGCG penetration through the skin. Whereas, in TC and NTC, there was clear significant difference in cumulative amount and flux of EGCG penetrated. These results showed that the cumulative amount of EGCG penetrated and penetration rate in TS was higher than ES, and TC was more promising than NTC. It was due to the transfersome suspension, green tea leaves extract that contained EGCG had been formulated in the form of lipid nanovesicles. This made the hydrophilic compound (EGCG) that has small partition coefficient ( $\log \mathrm{p}=0.48$ ) will be facilitated to penetrate through the lipid bilayer of skin rat when the drug was loaded into a lipid carrier..$^{13}$ Therefore, EGCG skin permeation of the cream loaded with transfersome of green tea leaves extract (TC) was higher when compared to the cream with just loaded of green tea leaves extract (NTC). However, formulating a transfersome suspension into the cream did not improve the cumulative amount and flux of EGCG penetrated. It can be seen from the comparison of cumulative amount of EGCG penetrated from TS, TC and NTC. The amount of EGCG penetrated from TS was still higher than TC and NTC. This occurred due to the presence of a cream base that can interfere the release of the drug into the skin. The use of excipients for the formation of a cream base makes the active ingredients more viscous. This was explained by Thakker, the viscosity of the drug influences the rate of drug release and penetration through the skin. ${ }^{32}$ Therefore, TS that formulated in the form of cream becomes more difficult to penetrate and only a few EGCG was penetrated through the skin.

\section{CONCLUSION}

It can be concluded that by formulating green tea leaves extract into a transfersomal cream, it could increase the cumulative amount and in vitro flux penetration of EGCG penetrated from the extract through the skin when compared to non-transfersomal cream.

\section{ACKNOWLEDGEMENT}

The authors are highly thankful to Universitas Indonesia who had given a financial support for this research, particularly for PITTA Research Grants 2017.

\section{CONFLICT OF INTEREST}

Authors declare that there is no conflict of interest.

\section{ABBREVIATIONS}

EGCG: Epigallocatechin gallate; TEM: Transmission Electron Microscope; \%EE: Entrapment Efficiency; IC: Inhibitor concentration; PDI: Polydispersity index; DPPH: Diphenilpicryl-Hydrazyl; TC: Transfersomal cream; NTC: Non-transfersomal cream; ES: Extract solution; TS: Transfersome suspension.

\section{SUMMARY}

In this study, transfersome formulation of green tea leaves extract ( $\mathrm{Ca}$ mellia sinensis L. Kuntze) was incorporated into a cream dosage form to enhance drug penetration, EGCG. An in vitro penetration study using Franz Diffusion Cells was conducted, and a non-transfersomal green tea leaves extract cream was prepared as a control. The quantification of EGCG penetrated in the in vitro penetration study was analyzed using a reverse-phase high performance liquid chromatography (RP-HPLC) method. This study showed that transfersomal cream could increase the cumulative amount and in vitro flux penetration of EGCG penetrated from the extract through the skin when compared to non-transfersomal cream.

\section{REFERENCES}

1. Namita P, Mukesh R, Vijay KJ. Camellia sinensis ( Green Tea ): A Review. Global J Pharmacol. 2012;6(2):52-9

2. Anand J, Upadhyaya B. Biochemical characterization and pharmacognostic evaluation of purified catechins in green tea (Camellia sinensis) cultivars of India. 3 Biotech. 2015;5(3):285-94. 
3. Primavesi L, Piantanida M, Pravettoni V. Studying Tea Polyphenols and Their Protective Effects on Skin. Polyphenols in Human Health and Disease. 2014;849-59.

4. Legeay S, Rodier M, Fillon L, Faure S, Clere N. Epigallocatechin Gallate: A Review of Its Beneficial Properties to Prevent Metabolic Syndrome. Nutrients. 2015; $7(7): 5443-68$

5. Mereles D, Hunstein W. Epigallocatechin-3-gallate (EGCG) for Clinical Trials: More Pitfalls than Promises. Int J Mol Sci. 2011;12(12):5592-603.

6. Anwar E, Utami TD, Ramadon D. Transfersomal Gel Containing Green Tea (Camellia sinensis L. Kuntze) Leaves Extract: Increasing in vitro Penetration. Asian Journal Of Pharmaceutical And Clinical Research. 2017;10(8):294-8.

7. Ramadon D, Wirarti GA, Anwar E. Novel Transdermal Ethosomal Gel Containing Green Tea (Camellia sinensis L. Kuntze) Leaves Extract: Formulation and in vitro Penetration Study. J Young Pharm. 2017;9(3):336-40.

8. Patel AR, Velikov KP. Non-covalent interactions of green tea polyphenols: Source of novel colloidal structures. Nova Biomedical. 2013;151-66. PMCid:PMC3696132

9. O'Neil MJ, Smith A, Heckelman PE, Obenchain JR, Gallipeau JAR, D'Arecca MA. The Merck Index. 13 th ed. New Jersey: Merck and Co. 2001.

10. Millsop JW, Sivamani RK, Fazel N. Botanical Agents for the Treatment of Nonmelanoma Skin Cancer. Dermatology Research and Practice. 2013;2013:1-9.

11. Lee SC, Chan WK, Lee TW, Lam WH, Wang $X$, Chan TH, et al. Effect of a prodrug of the green tea polyphenol (-)-epigallocatechin-3-gallate on the growth of androgen-independent prostate cancer in vivo. Nutr Cancer. 2008;60(4):483-91.

12. Benson HAE, Watkinson AC. Transdermal and Topical Drug Delivery: Principles and Practice. Singapore: John Wiley and Sons, Inc. 2012.

13. Patel R, Singh SK, Singh S, Sheth NR, Gendle, R. Development and characterization of curcumin loaded transfersome for transdermal delivery. J Pharm Sci Res. 2009;1(4):71-80.

14. Sarmah P, Bhupen K, Anil KS. Transfersomes based transdermal drug delivery: An overview. Int J Adv Pharm Res. 2013;4(12):2555-63.

15. Molyneux P. The Use of Stable Free Radical Diphenilpicryl-Hydrazyl (DPPH) For Estimating Antioxidant Activity. Songklanarin J Sci Tech. 2004;26(2):211-9.

16. Pantone I. Simulations of Pantone Matching System Colors. New Jersey. 2004.

17. Anwar E, Ramadon D, Harmita. Formulation and Evaluation of Gel and Emulgel of Chili Extract (Capsicum Frutescens L.) As Topical Dosage Forms. Int J Pharm Pharm Sci. 2014;6(3):13-6.
18. Fangueiro FJ, Parra A, Silva AM, Egea MA, Souto EB, Garcia ML, et al. Validation of a high performance liquid chromatography method for the stabilization of epigallocatechin gallate. Int J Pharm. 2014;475(1-2):181-90.

19. Gramza A, Pawlak-Lemanska K, Korczak J, Wasowicz E, Rudzinska M. Tea extracts as free radical scavengers. Polish J Env Stud. 2005;14(6):861-7.

20. Dang S, Gupta S, Bansal R, Ali J. Nano-encapsulation of a Natural Polyphenol, Green Tea Catechins: Way to Preserve Its Antioxidative Potential. Free Radicals in Human Health and Disease. 2015;397-415.

21. Benson HA. Transfersomes for transdermal drug delivery. Expert Opin Drug Deliv. 2006;3(6):727-37.

22. Ahmed S. Green tea polyphenol epigallocatechin 3-gallate in arthritis: progress and promise. Arthritis Res Ther. 2010;12(2):208.

23. Verma P, Pathak K. Nanosized ethanolic vesicles loaded with econazole nitrate for the treatment of deep fungal infections through topical gel formulation. Nanomedicine : NBM. 2012;8(4):489-96.

24. Malvern Instruments. Dynamic Light Scattering Common Terms Defined. $2011 ; 1-6$.

25. Ramadon D, Pramesti SS, Anwar E. Formulation, Stability Test And in vitro Penetration Study Of Transethosomal Gel Containing Green Tea (Camellia sinensis L. Kuntze) Leaves Extract. Int J Appl Pharm. 2017;9(5):91-6.

26. Ramadon D, Anwar E, Harahap Y. in vitro Penetration and Bioavailability of Novel Transdermal Quercetin-loaded Ethosomal Gel. Indian J Pharm Sci. 2017;79(6):948-56.

27. Shiny A, Toomu MC, Dhurke RK. Enhanced dermal delivery of nadifloxacin using liposomes. Int J Appl Pharm. 2016;8(4):53-9.

28. Sou K. Electrostatics of carboxylated anionic vesicles for improving entrapment capacity. Chem Phys Lipids. 2011;164(3):211-5.

29. Chaudhary H, Kohli K, Kumar V. Nano-transfersomes as a novel carrier for transdermal delivery. Int J Pharm. 2013;454(1):367-80.

30. Jain S, Jain P, Umamaheshwari RB, Jain NK. Transfersomes-A Novel Vesicular Carrier for Enhanced Transdermal Delivery: Development, Characterization, and Performance Evaluation. Drug Dev Ind Pharm. 2003;29(9):1013-26.

31. Sinko PJ. Martin Farmasi Fisika dan Ilmu Farmasetika. Jakarta: Penerbit Buku Kedokteran EGC. 2011;706.

32. Thakker K, Chern W. Development and validation of in vitro release tests for semisolid dosage forms - case study. Dissolu Technol. 2003;10(2):10-6.

Article History: Submission Date : 01-02-2018; Revised Date : 15-02-2018; Acceptance Date : 14-05-2018.

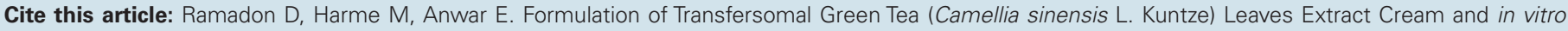
Penetration Study Using Franz Difussion Cell. J Young Pharm. 2018;10(2)Suppl:s63-s68. 